\title{
The Emergence of Innovation Education: Trends and Challenges
}

\author{
Guangmei Lin ${ }^{1, ~ a, ~ Z h e n ~ K o n g ~}{ }^{1, ~ c}$, Kun Bai ${ }^{2, ~ b, *, ~ L i n g h a n ~ K o n g ~}{ }^{3}$ \\ ${ }^{1}$ Beijing Information Technology College, No. 5, Fangyuanxilu, Chaoyang District, Beijing, China \\ ${ }^{2}$ University of International Relations, No. 12, Poshangcun, Haidian District, Beijing, China \\ ${ }^{3}$ Beijing Bayi School, No. 29, Suzhoujie, Haidian District, Beijing, China \\ ${ }^{a}$ Lingm@bitc.edu.cn, ${ }^{b}$ Baikun@uir.edu.cn, ${ }^{c}$ Kongz@bitc.edu.cn \\ *Corresponding author
}

Keywords: Student; Vocational college; Innovation; Education

Abstract: This paper focuses on the trends and challenges in innovation education in the 21st century. It is aimed at looking for advice, ideas and inspiration for the effective education in Chinese vocational colleges. Every business plan should provide insights into the future strategy. It is important for colleges and universities to plan the orderly transition of the education as it grows and develops. Milestone scheduling is a step-by-step approach to illustrate accomplishments in a piecemeal fashion. These milestones can be established according to any appropriate timeframe, such as quarterly, monthly or weekly. Among the wide range of tools available to innovators, coaching is increasingly popular as a support structure. It addresses the limitations of "classic" support measures predicated on passive absorption of knowledge and ready-made formulas in a lecture-type context where entrepreneurs are told what they "must" do, without being given the opportunity to really become involved.

\section{Introduction}

Innovation is a dynamic process of vision, change, and creation. It requires an application of energy and passion towards the creation and implementation of new ideas and creative solutions. Essential ingredients include the willingness to take calculated risks - in terms of time, equity, or career; the ability to formulate an effective venture team; the creative skill to marshal needed resources; and fundamental skill of building solid business plan; and finally, the vision to recognize opportunity where others see chaos, contradiction, and confusion. The younger generation of the 21 st century is becoming the most entrepreneurial generation since the Industrial Revolution.

\section{Challenges of "Power of One"}

It has been pointed out that so many innovation programs have been started and driven to success by one professor or director. Critics argue that our field is weak because many E-Programs hinge on that one person's drive and determination. I argue that it is courage and passion of individuals who have developed courses, programs, centers, etc., that are now beginning to take 
root in colleges. The "power of one" to make a difference is more apparent in the innovation field than in any other academic discipline. The administrative support in colleges has been sporadic at best. The reason I have heard so often is the constant "changing of the guard." Presidents, provosts, and deans are continuously changing among colleges, and with those position changes come values and vision changes. Innovation courses and programs have suffered through differing philosophies of senior officers in Chinese colleges. While we cannot put an artificial freeze on these positions, we can move the innovation field into a leadership role at our institutions. It is hard for any senior officer to ignore a program that stands in a leadership and influential position among students, alumni, business leaders, donors, and other faculty. This is the base of real leadership power, and innovation deserves nothing less in the 21st century.

\section{Career-oriented Mentoring}

Consistent with the recognition of employees as a competitive resource and therefore a source of competitive advantage, many colleges have introduced career development programs combined with innovation course, the objectives of which include: (a) to enhance employee competencies, (b) strengthen employee organization linkages and (c) provide employees opportunities to satisfy their career concerns while contributing to organizational goals. Organizational career development refers to specific human resource activities that are designed to help match employee interests and capabilities with organizational opportunities. Such formalized programs essentially involve the readiness activities necessary for skill and knowledge to fully prepare an individual to pursue and obtain jobs of greater authority and responsibility. The distinction between formalized and informalized mentoring program is particularly important. Thus, in the implementation of formalized mentoring programs, emphasis should be on careful planning and making it as less 'hierarchically-imposed' as possible. To this end, attention should be devoted to careful selection of mentors based principally on the criteria of willingness to invest time and energy in the relationship and having had broad and extensive experience in key positions at higher organizational levels in order to expose protégées to activities at these levels. Second, there should be adequate orientation in terms of defining and clarifying protégé-mentor roles and expectations respectively. Finally, both mentors and protégées should be involved in the process of matching protégées to mentors. The incorporation of these suggestions into the planning and implementation of a formalized mentoring relationship should enhance the flexibility of such a relationship and the beneficial outcomes to both individuals and organizations. In a Chinese context, this view is eloquently distilled in Sun TZU'S admonition cited that 'Do not repeat the tactics which have gained you one victory, but let your methods be regulated by the infinite variety of circumstances' or, as in this context, career goals.

\section{Entrepreneurial Education}

Innovation is a significant driver of improvements in social welfare and economic prosperity. A mountain of empirical evidence points to the positive and statistically robust link between innovation and economic growth cross a broad spectrum of performance measures. The college-based innovation ecosystem comprises the physical spaces where innovators interact; the alignment of institutional objectives; access to resources like laboratories, researchers and knowledge transfer; market-driven orientation for research; participation of the business community; participation of venture capital firms; and many other things. Education should really accelerate one's self-efficacy. Self-efficacy is an important trait that enables a person to have confidence in discovering opportunities and when contemplating the feasibility of starting a business. BITC College research shows that taking two or more core elective courses positively influenced the intention to become an innovator both at the time of graduation and long afterward. The research 
has found that entrepreneurship students are three times more likely to be self-employed. They are divided into macro and micro approaches. We also examined the various generations of entrepreneurs and discussed innovation as a pathway to human freedom. There are some quite distinct entrepreneurial differences in the generations. Baby boomers have the most amount of wealth, connections and business experience, all of which are needed to make a business successful. Soon Generation Z, those born 1995-2009, who never knew the pre-Internet world, will be graduating from school and colleges and entering the workforce. They will be followed by Generation Alpha, those born after 2010. For this generation, smart phones have always existed. In 2017, Chinese teenagers were spending, on average, almost an entire day of the week on their smart phones. The children of older, wealthier parents with fewer siblings, they are already being labeled materialistic. The book you are holding is all about finding your own personal pathway to entrepreneurship. Amartya Sen, winner of the 1998 Nobel Prize in Economics, argues that economic activity is the objective and the primary means of enhancing human freedom: 'The usefulness of wealth lies in the things that it allows us to do - the substantive freedoms it helps us to achieve'. For Sen, the highest expression of freedom is the ability to choose what kind of life one wants to lead, to be the sole proprietor of one's own destiny. Individuals must be free to choose their own accounts of the good life inspired by innovation education. That freedom resides in such things as the right to participate in market exchange itself. Innovation is a mode of self-actualization. Innovation offers a positive alternative to the ideologies of violence and division that can all too often fill the void when young people don't see a future for themselves.

\section{Effective Training}

Effective innovators are often described as quick learners. Unlike many people, however, they also have a strong desire to know how well they are doing and how they might improve their performance. In attempting to make these determinations, they actively seek out mentors and use their feedback. Feedback is also central to their learning from their mistakes and setbacks. Successful innovators believe in themselves. They do not believe the success or failure of their venture will be governed by fate, luck or similar forces. They believe their accomplishments and setbacks are within their own control and influence and that they can affect the outcome of their actions. This attribute is consistent with a high-achievement motivational drive, the desire to take personal responsibility and self-confidence. Start-up innovators face uncertainty multiplied by constant change. This introduces ambiguity and stress into every aspect of the enterprise. Setbacks and surprises are inevitable; lack of organization, structure and order is a way of life. Yet successful innovators thrive on the fluidity and excitement of such an ambiguous existence and generally have a high tolerance for ambiguity. Innovators use failure as a learning experience and generally have a high tolerance for failure. The iterative, trial-and-error nature of becoming a successful innovator makes serious setbacks and disappointments an integral part of the learning process. They do not become disappointed, discouraged or depressed by a setback or failure. Many believe they learn more from their early failures than from their early successes. The emotions generated by failure can interfere with the learning process. It appears likely that creativity is less a genetic trait than a cultural characteristic - one that can be learned. Entrepreneurs know where they want to go. They have a vision or concept of what their business can be. For example, Steve Jobs, one of the founders of Apple Computer Inc., wanted his business to provide microcomputers that could be used by everyone from schoolchildren to businesspeople. The computer would be more than a machine. It would be an integral part of the person's life in terms of learning and communicating. This vision helped make Apple a major competitor in the microcomputer industry. In many cases, this vision develops over time as the individual begins to realize what the business is and what it can become. 
Passion is a fundamental emotional experience for innovators. Passion is an expression constructed by the innovator to provide a coherent understanding to an emotional experience of intense arousal and energy mobilization involving an innovator and his or her venture. Moreover, entrepreneurial passion is characterized by a discrete emotion that is quite intense, having been described as an underlying force that fuels our strongest emotions, or the intensity felt when engaging in activities that are of deep interest, or the energy that enables innovator to achieve peak performance. Successful innovators need to have highly qualified, well-motivated teams that help handle the venture's growth and development. Teams with past experience together can have an even stronger effect on the new venture's survival and successful growth.

\section{Summary}

The recent growth and development in the curricula and programs devoted to innovation education have been remarkable. The number of Chinese colleges that offer courses related to innovation has grown from a handful in the 1990s to over 1,000 in 2018. In the midst of this huge expansion remains the challenge of complete academic legitimacy for innovation. There are critical challenges that lie ahead.

\section{Acknowledgement}

This research was financially supported by Beijing Information Technology College Research Subject.

\section{References}

[1] Kuratko, D.F. \& Hodgetts, R.M. Entrepreneurship: Theory, process, practice [M]. SouthWestern College Publishers,2004.

[2] Allen, T. D., \& Poteet, Developing effective mentoring relationships: Strategies from the mentor's viewpoint[J]. Career Development Quarterly, 1999(48) 59-73.

[3] Thorp, H. and Goldstein, B, Engines of Innovation: The Entrepreneurial University in the Twenty-First century[M]. Chapel Hill, University of North Carolina Press, 2010. 